\title{
TEACHING BUSINESS ENGLISH ONLINE. ASSIGNMENT ACTIVITIES AND TESTS IN MOODLE
}

\author{
loana Claudia HOREA ${ }^{1}$, Cristina Laura ABRUDAN ${ }^{2}$ \\ 1,2 Department of International Business, Faculty of Economics, University of \\ Oradea, Oradea, Romania \\ 1 ioanahorea@gmail.com \\ 2cabrudan2003@yahoo.com
}

\begin{abstract}
In many universities around the world, the current pandemic situation confined the academic process to online interactions alone, with no physical presence in a class, the 'face-to-face' classes being held by means of applications or programs that provide video conferences facilities. Besides these tools for live communication, most universities - among which ours, as well - have started to make extensive use of the e-learning Moodle platform. Especially designed for the distance learning form of education, the Moodle platform has previously been used in our university mostly by the teachers involved in the distance learning form, particularly for the purpose of providing the distance learning students with study materials and other resources of interest for the subject - through the resources uploaded on the pages of the discipline -, for communication - by means of forums and chat rooms -, and for enabling a few tests and assignments along the semester. Now, with everything going online, the vast range of facilities this application offers has come to be discovered by all academics involved in the instruction process. In both synchronous and asynchronous activities organised by means of the platform, the user will find useful a series of facilities offered by the platform. Among these, the current study will refer to several diverse possibilities of using the activities of Assignment and Test for the classes of English for Business, with a series of examples of exercises that were created by means of these Moodle tools. The regular file upload assignment in which the student were instructed what to prepare, compose or solve, and upload at the specific button has now, with experience, 'grown' obsolete, more interesting online text types of assignment being preferred, such as video or audio records, texts written directly online in the applications or others types following templates and using materials posted. As for the tests, besides the basic types - more straightforward and easy to create - such as: multiple choice drills, matching, true / false, short answers, or drag and drop, there will be exemplifications of the embedded answers (cloze) type, which requires audacity and willingness from the teacher to put in more effort to prepare and self-instruct on how to use and enter special codes in order to create complex exercises. Needs teach us and eventually the results prove indeed rewarding and worth the effort.
\end{abstract}

Keywords: Business English, online teaching, Moodle platform, assignment activity, tests.

JEL classification: Z13, Y80, 121 


\section{Preliminary observations}

\subsection{Previous preoccupations}

Moodle is a well known platform for distance learning that has been implemented and used with universities around the world for several years now. The preoccupation for teaching languages through Moodle has been a concern of several researchers in the field.

As soon as the year 2009, a book with online language-learning activities using Moodle platform is published by Jeff Stanford, bringing a series of examples on "how to use Moodle 1.9 to create complete, usable activities." (Stanford, 2009)

In 2010, Moodle has already become a fashion, and teachers and researchers, as Phil Bird, began to share creative ideas, tools and techniques, used with their learners. (Bird, 2010)

In 2011, Warth-Sontheimer presented in details, with concrete examples, five Moodle activities - Forums, Chat, Wiki, Assignment, Glossary and Games - that will "take you very far", focusing on "using the individual activities for language teaching in particular." (Warth-Sontheimer, 2011, p.11)

Others see Moodle an advantage in itself, a step towards progress in language teaching and learning: "The multi-functionality of Learning-Management System (LMS) such as Moodle is integrated in English language classrooms to enhance students' learning." (Suksan; Nutprapha, 2010)

Some years later, Moodle had taken ground and more and more researchers started to dig into its utility and benefits. Reviewing an electronic language courses they developed and implemented at higher education level, Aikina and her fellow researchers come to the conclusion that "electronic courses designed by means of the e-learning platform Moodle are ideally suitable for the efficient blended learning implementation." (Aikina et all, 2015)

Learners, as always open to the new, to technology and innovative systems seem to find these courses and the activities they provide much more appealing than the classical lectures and seminars "Most students reported greater satisfaction from, engagement in and motivation for learning." (Gluchmanova, 2016, p.497)

There are, nevertheless, opinions to the contrary, as the research of Khabbaz and Najjar shows: "The findings imply that learning language through Moodle-based teaching materials impede the process of being autonomous language learners." (Khabbaz, Najjar, 2015)

\subsection{Current concerns}

Year 2020 comes with unforeseen challenges in education, as well as in most domains of human activity. The current circumstances, of Covid 19 pandemics, have brought about a great deal of new demands in the process of teaching and learning. In many cases, the academic process was confined to online interactions alone, with no physical presence in a class, the 'face-to-face' classes being held by means of applications or programs that allow "video conference", such as: Zoom, Google Meet, Microsoft Teams. Besides these tools for direct, live communication, most universities - among which our university - have used, intensively and extensively, the e-learning platform Moodle. 


\section{Assignment activities}

TOM XXX, $2^{\text {nd }}$ Issue, December 2021

\subsection{Regular assignments}

The uploaded files assignment type has been the most commonly used in previous years for projects, articles, even exercise solving, as homework or along the scheduled classes, as individual or group activity. But this previously so commonly used type of assignment consisting of posting requirements and then checking the uploaded files with the students' work on the exercises, articles or projects has kind of fallen into disuse or at least ordinariness.

Moodle nevertheless provides the possibility to have more attractive as well as straightforward types of assignment. These not only can offer diversity and neuroplasticity to the users but are also more user friendly. They can be less time consuming and more appropriate to the use during classes, due to the direct, online work they imply.

\subsection{Online activities}

Thus, more interesting online text types of assignment seem to be favoured, even spicing up the individual class activity, with video or audio records, texts written directly online in the applications or others types following templates and using materials posted.

Some of these can be seen in the figures that follow. They represent actual activities that were done with a class of first year students during their practical course classes. Names, contacts, video records of respondent students have been blurred for data protection reasons.

Figure 1 shows the pages representing the requirement in the assignment of audio recording, respectively, two answers registered for this assignment. The instructor hears the audio recordings posted, by clicking the play button directly from the view and grading page.

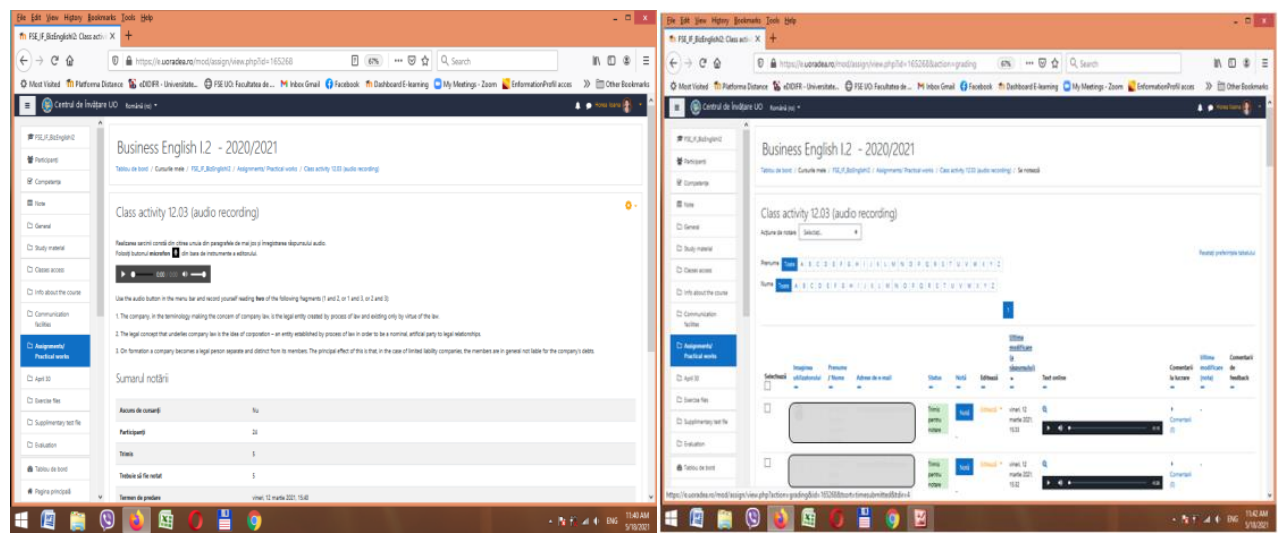

Figure 1. Online audio recording - assignment task page and response page

Figure 2 represents the task page and the response page for the assignment consisting in filling in a template file. As seen in the first picture, the template file is a word document attached to the assignment instruction page. This means that it 
becomes visible together with the assignment, i.e., if the case, at the moment the assignment's restrictions are over, conditions are met and it becomes available.

While figure 3 presents the page with instructions on a video recording assignment and then the view page with students registered activities, figure 4 shows instruction and results pages for online text assignment. The last example in the subtitle, figure 5 , brings about the design page of a questionnaire activity and that of its response page. It is quite obvious that at least two of these types of assignments can be very important for the course at stake: The video and audio recording facilities are of much value for language classes especially. They provide the teacher with records of the students' pronunciation, intonation and ability to render a text in a natural and proper way. Records can be later revisited, analysed and addressed, as well as they can stay as landmarks and proofs for improvement and progress.

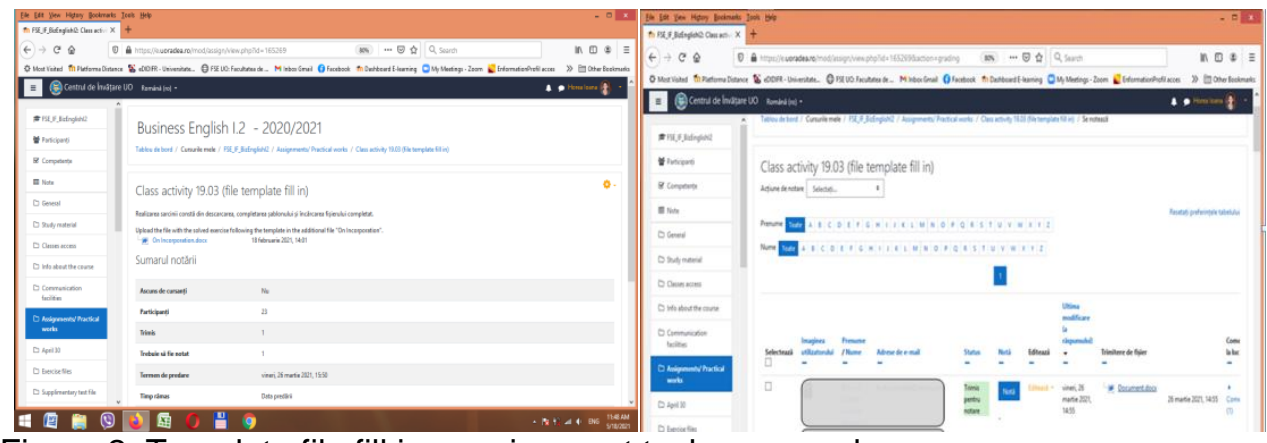

Figure 2. Template file fill in - assignment task page and response page

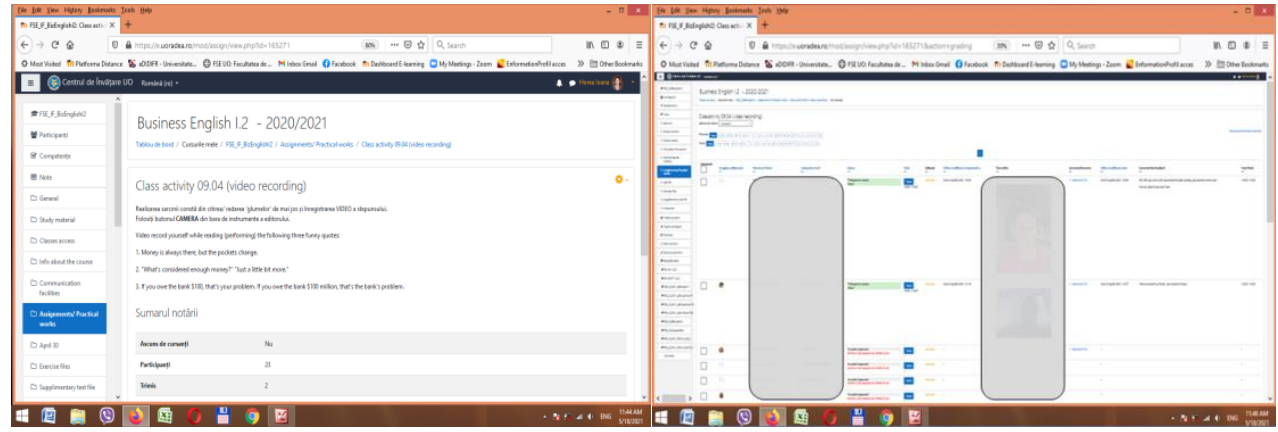

Figure 3. Online video recording - assignment task page and response page 


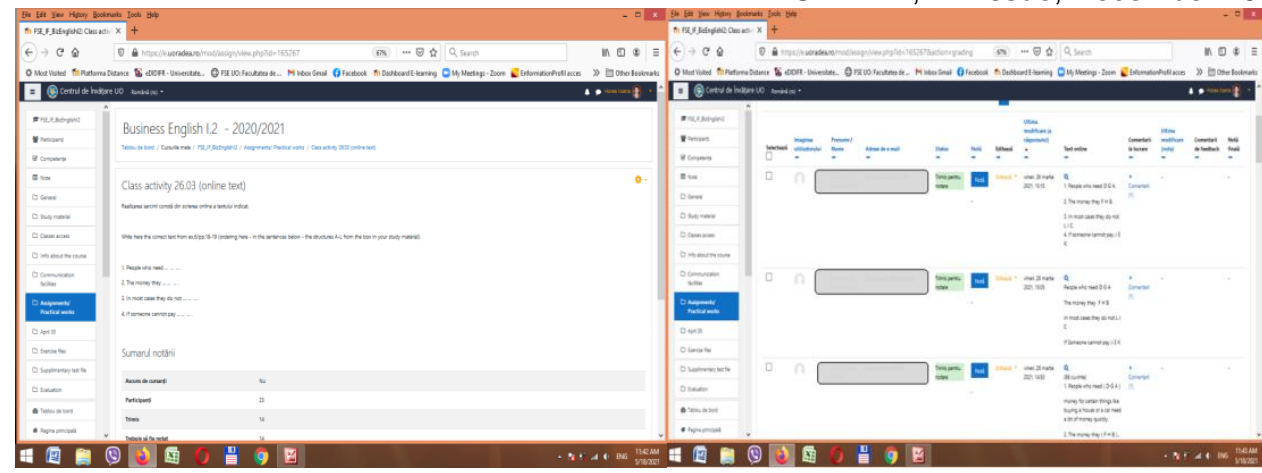

Figure 4. Online text writing - assignment task page and response page

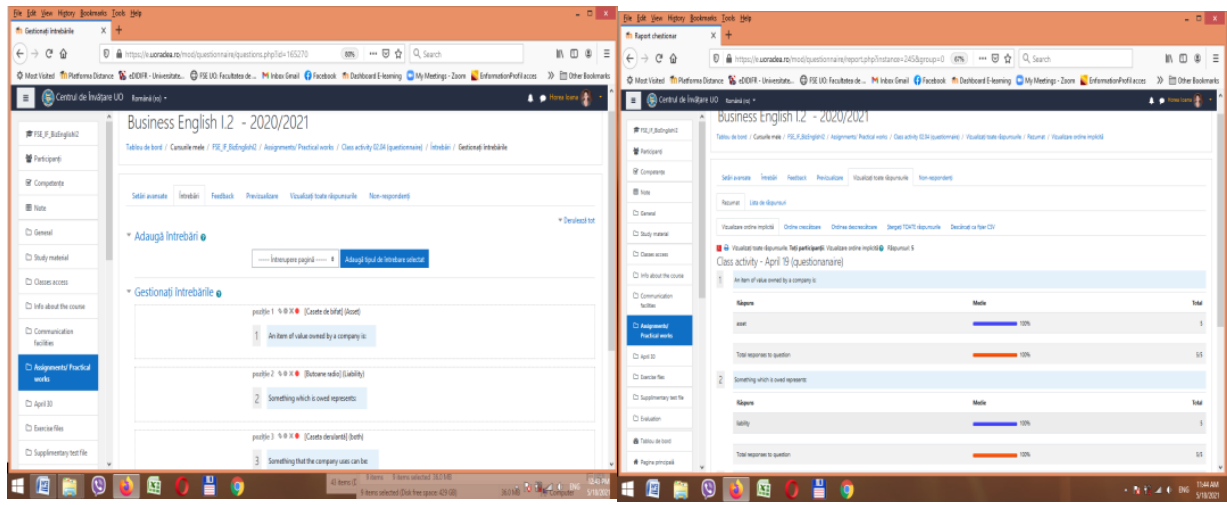

Figure 5. Online Questionnaire - questions editing page and response page

\section{Testing}

\subsection{Ready-made vs. complex test types}

The online test with multiple choice drills has been one of the first activities used with Moodle classes and evaluations and its usefulness and advantages are undoubtedly recognised. It has always been and will probably remain one of the best applications for rapid testing both during classes and for evaluations.

Various exercises such as matching, short answers, numeric answers, filling in gapped texts, drag and drop exercises, arranging fragments in texts, cloze text multiple choice from variants button, true/false, yes/no, diagram description, as well as combinations of these types make tests not only more complex and realistic but also more appealing and appropriate.

For matching, true/false, yes/no exercises, Moodle offers question types especially designed and the use of these is quite straightforward.

An example of matching type exercise and its configuration is in figure 6 . 


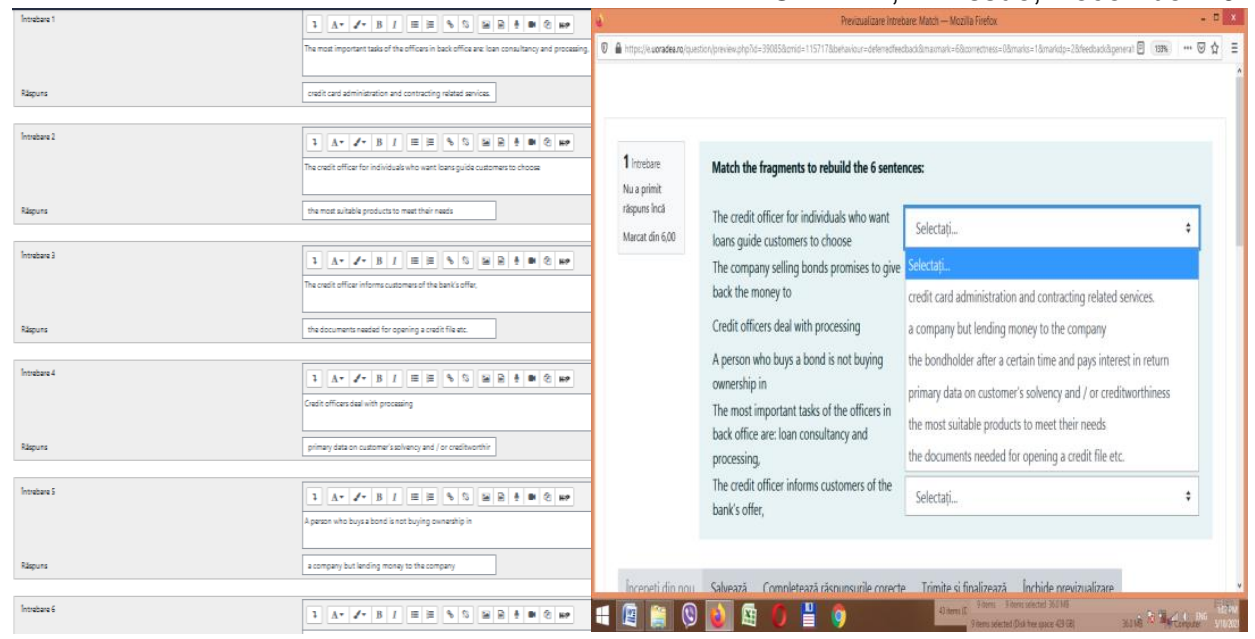

Figure 6. Creation and result for a matching exercise type

\subsection{Designing complex tests}

The creation of the other complex types aforementioned require more work as the embedded answers (cloze) question type has to be used (Figure 7a).

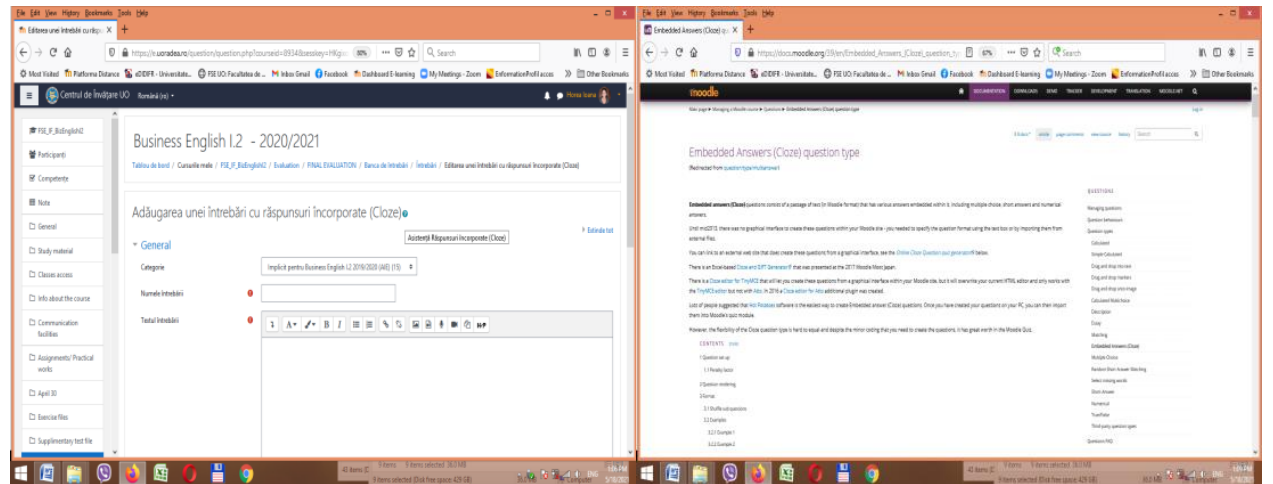

Figure 7a-b. Embedded answers (cloze) question type and design-instruction help-page

There are several formatting instructions that need to be strictly and attentively followed by the instructor in order to programme the application correctly and get the desired result.

Further assistance is needed so that the help section (Figure $7 b$ ) will surely be used, and the page with formatting instructions will have to be analysed.

\subsection{Examples of coding and final aspects of complex tests}

When editing the questions, the instructor has to accurately use the codes, to instruct the soft "talking" its language, so as the application can decrypt it properly and render the desired result. The exercises resulting from such encryptions used in their instructions will look like any normal exercises that are regularly used in printed format materials. 
Some examples can be seen in the figures of the subsections that follow.

\subsubsection{Giving short numerical answers}

The end result will be similarly looking exercises with gapped text in which numbers of the correct answers from those listed should be introduced by the respondent from the keyboard. The design, though, can be produces either by using the 'shortanswer' instruction and identifying the right one among all numbers listed, by the sign of equality placed in front of it, or simply by using the 'numerical' instruction followed only by the right number after the sign of equality. The latter variant is more appropriate in this situation, the former being more useful with longer answers to be typed. Such longer answers may be words or groups of words, either to choose from a given list or to just fill in according to specific requirements. For instance, as seen in the last subtitle here, 3.1.8., words derived from the ones given are required to be typed, checking knowledge of affixation and word formation.

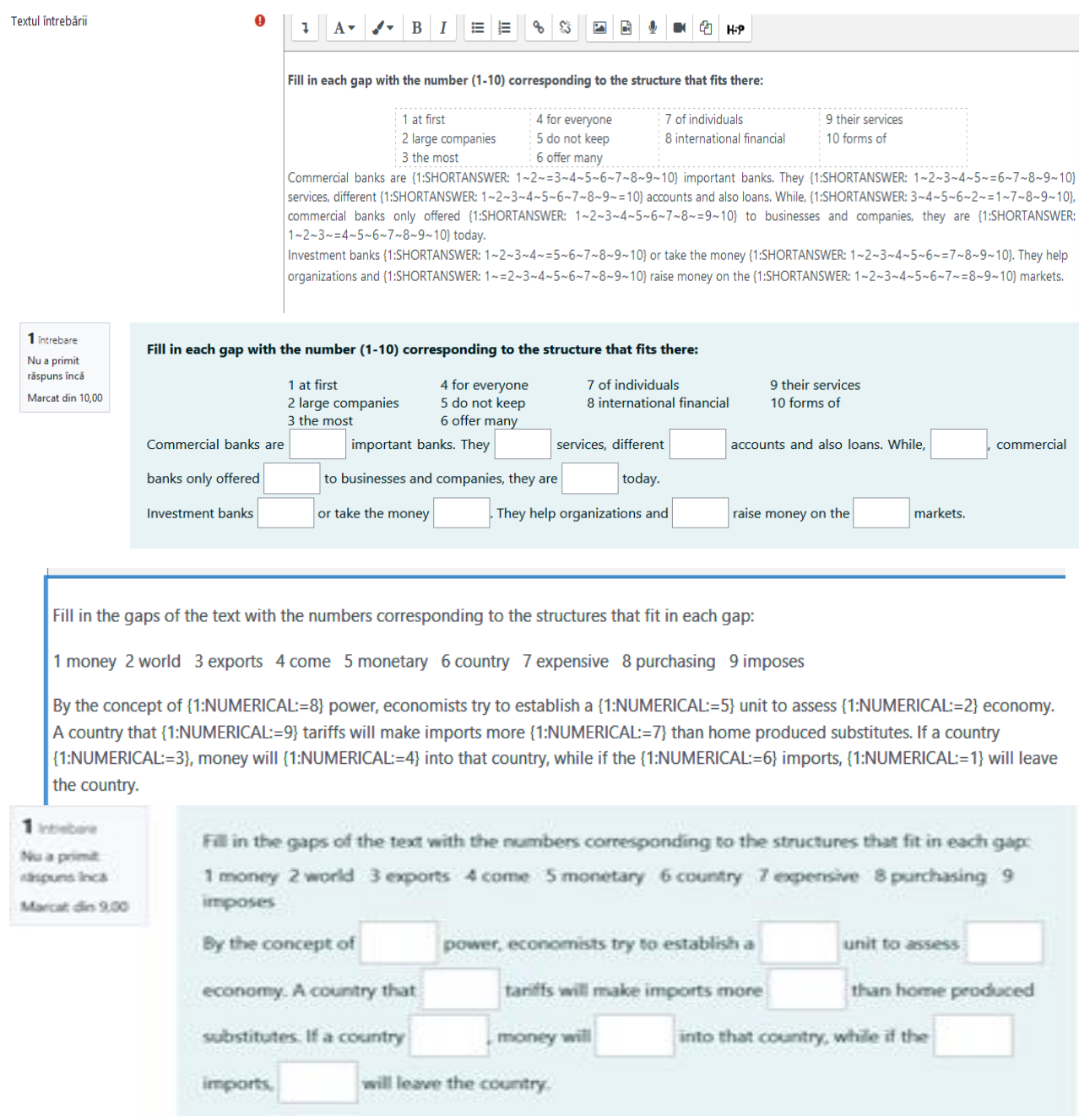


Figure 8 Coding and result for short numerical answers

\subsubsection{Image-text correlation}

Again using the 'numerical' instruction, the students can be asked to identify structures describing pictures, images, or drawings they are presented. The image in uploaded in the text of the question and then the descriptions are given and identified as correct by introducing the right number in the 'numerical' instructions. Further exercises are very pertinent in this situation. Thus, having in the first part several numbered speech bubbles and direct speech enunciations to choose from and match, a next part can be easily created. That latter part can be designed for checking knowledge of indirect speech. This can be done as in the example in figure 9 , by multiple choice questions having several variants from which to choose the correct transformation of the given enunciations into indirect speech. The variants will be introduced by the 'multichoice' instruction, or one of its variants, 'mch' - for horizontal design - or ' $m c v$ ' - for vertical design, as in the example below.

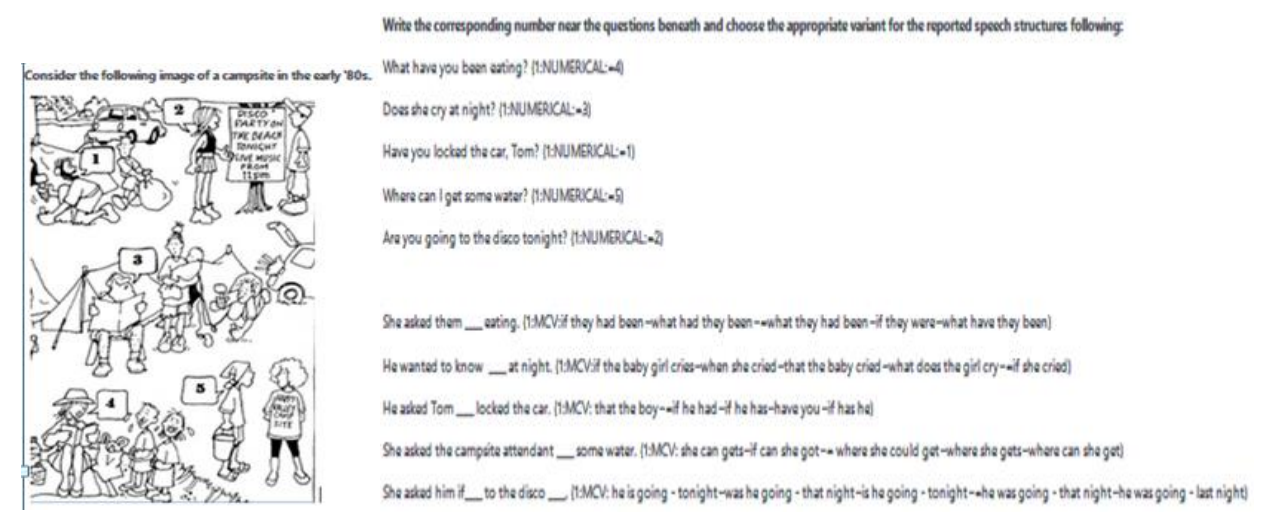



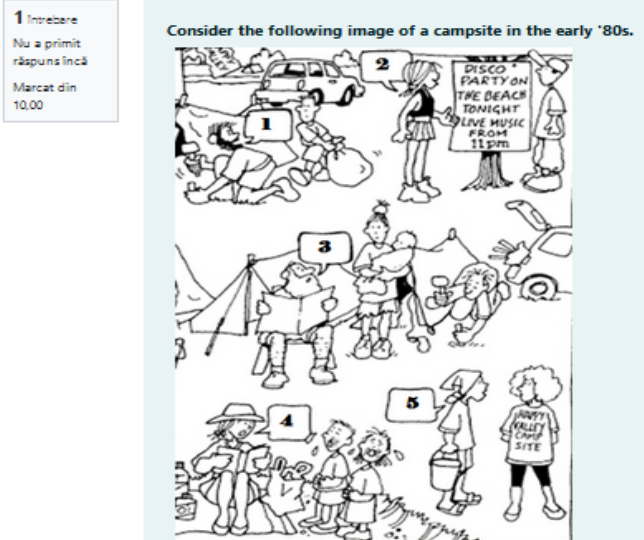

Write the corresponding number near the questions beneath and choose the appropriate variant for the reported speech structures following: What have you been eating? $\square$
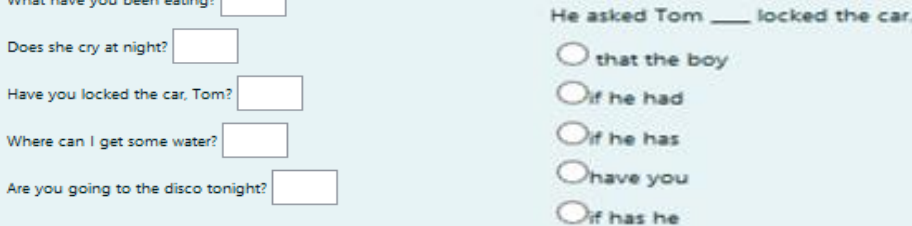

She asked them _ eating.

She asked the campsite attendant some water.

if they had been

She can gets

Owhat had they been

Oif can she got

Wwat they had been

Owhere she could get

Oif they were

Wwere she gets

Dwhat have they been

Owhere can she get

He wanted to know ___ at night.

She asked him if __ to the disco

Oif the baby girl cries

Ohe is going - tonight

Owhen she cried

Phat the baby cried

Owhat does the girl cry

Oif she cried

Owas he going - that night

Ois he going - tonight

Ohe was going - that night

Ohe was going - last night

Figure 9. Coding and result for image discussion (and reported speech)

\subsubsection{Diagram/graph description}

Inserting graphs or diagrams such as in the example below ("Describing charts" British Council, 2020), the encoded text can then be added to the text of the exercise in the creation page.
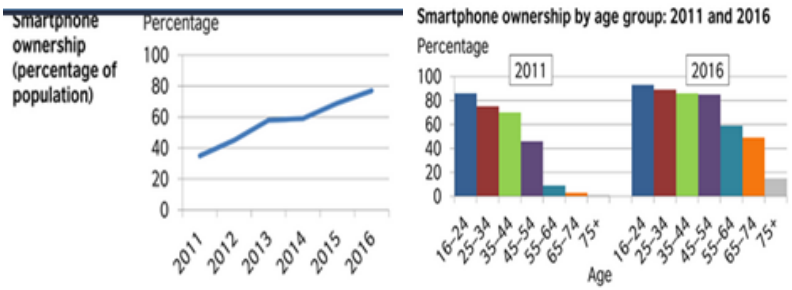


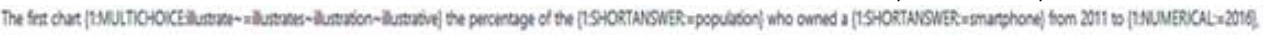

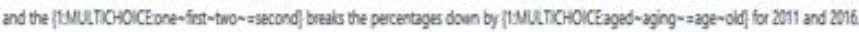

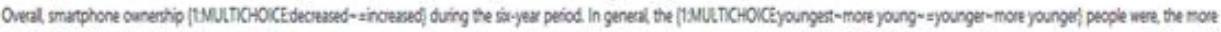

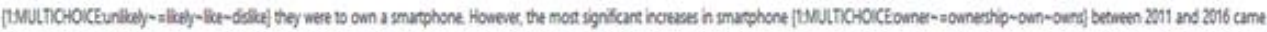

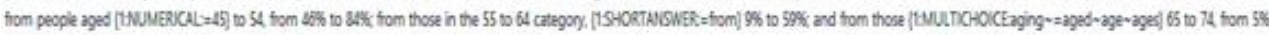

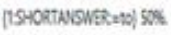

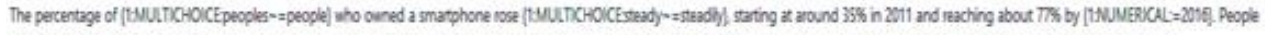

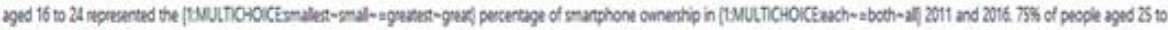

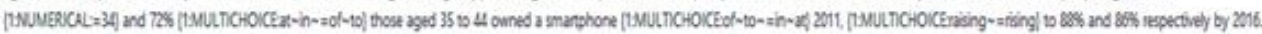

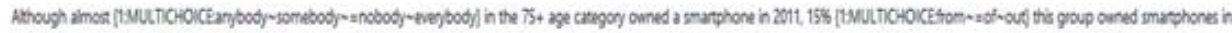
[1MULTOHOKE:2013-2014-2015-2016,

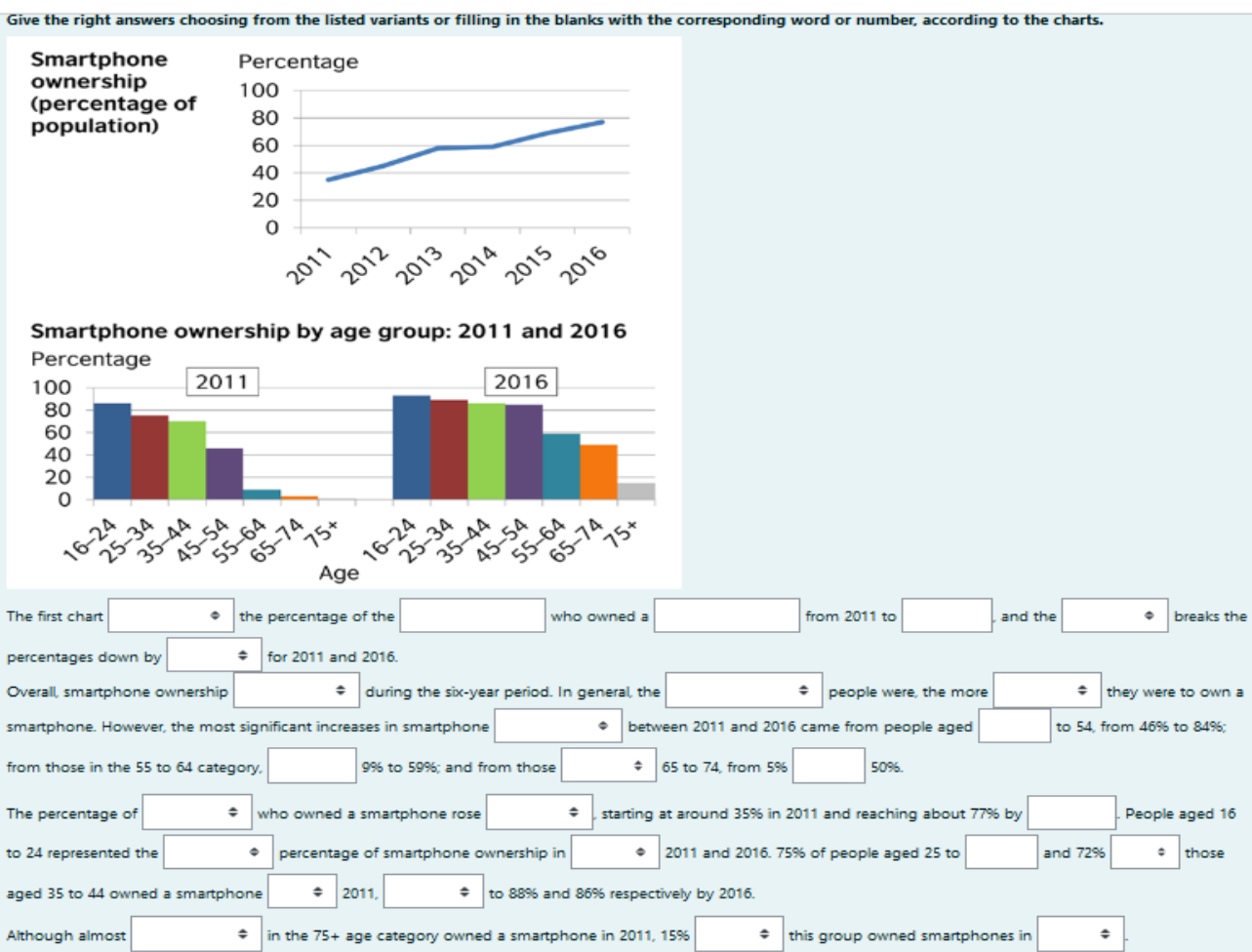

Figure 10. Coding and result for diagram discussion

This will result in a really professional looking outcome, an attractive exercise of graph description, such as seen in figure 10.

For encoding, all three instructions previously presented have been used, 'numerical', 'shortanswer' and 'multichoice'. This selection was resorted to for a combined and complex design of the end result. Thus, the final drill contains gaps to fill in with short words or numbers and selection arrow buttons to choose one variant from the ones displayed when clicking the arrows.

\subsubsection{Filling in with the right structure}

Exercises with words or structures to be placed in the right position in a text can be also created by using the drag and drop tool. This is encoded by inserting in 
the text numbers between double square brackets and then indicating the right answer for each numbered option. To have them presented in an identical design, the same group is selected for all words introduced, as seen here, in figure11, where group $A$ is chosen for all words.

The result will be an exercise consisting of a gapped text and the words/structures listed below it. The latter appear in boxes that can each be selected and dragged with the left button of the mouse kept pressed and then released to drop the content in the correspondent gap in the text. The shuffle button situated at the beginning of the options introduction fields has to be selected in order to have the structures displayed in the resulted exercise in a randomised order. Else, they are going to be listed exactly in the right order, which will reduce the exercise to a simple dexterity one, of exercising the mouse handling skill of dragging and dropping.

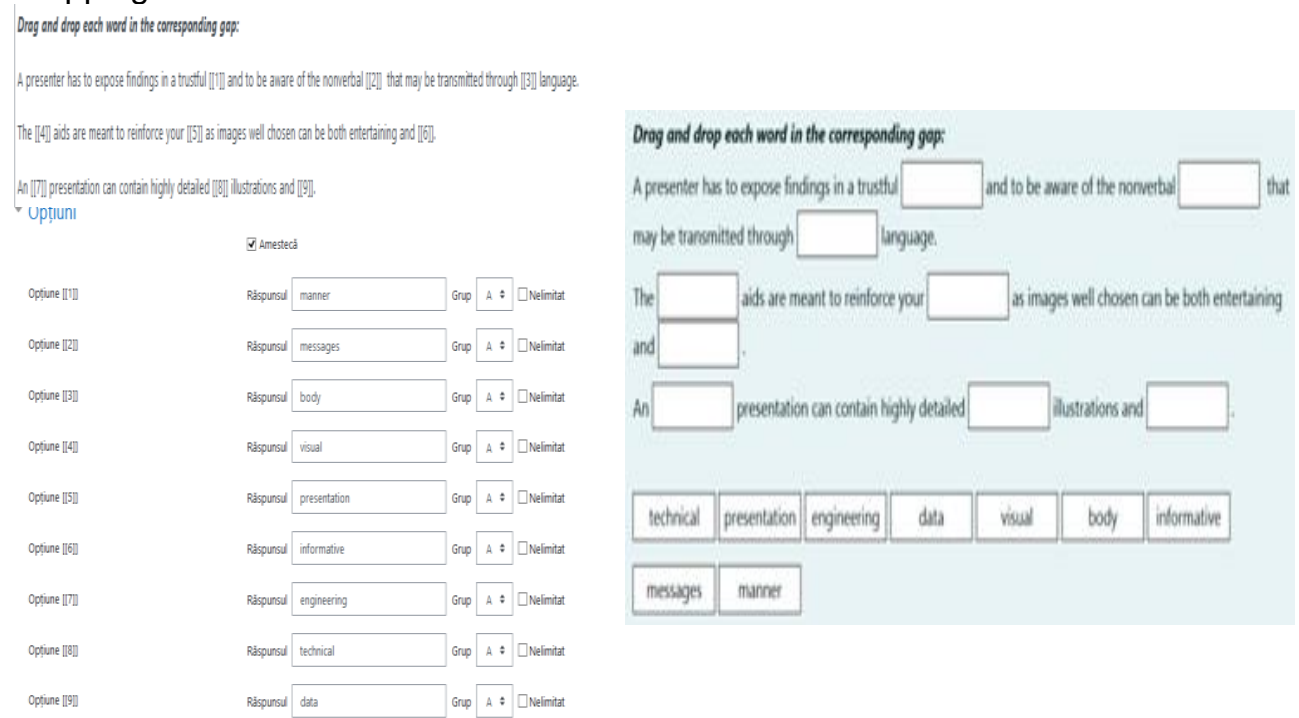

Figure 11. Coding and result for filling in a gapped text

\subsubsection{Arranging fragments in the right order}

Placing fragments in the correct order to get sentences is another type of exercise that can result from using the drag and drop tool. This time the structures that are to form distinct sentences can be identified, featuring different designs - colour and shape of the boxes, as seen in the last part of figure 12 - the image of the end result, the exercise created. This design is produced by selecting different groups for them, as seen in the middle part, which shows the way options are introduced: group $A$ for the structures 1-6 belonging to the first sentence, group B for the structures 7-10 that belong to the second sentence, and group $C$ for the last 5 structures that are to form the third sentence. 
To work shifts means [[1]] [[2]] [[3]] [[4]] [[5]] [[6]]. SME [[7]] [[8]] [[9]] [[10]].

The diagram [[11]] [[12]] [[13]] [[14]] [[15]].
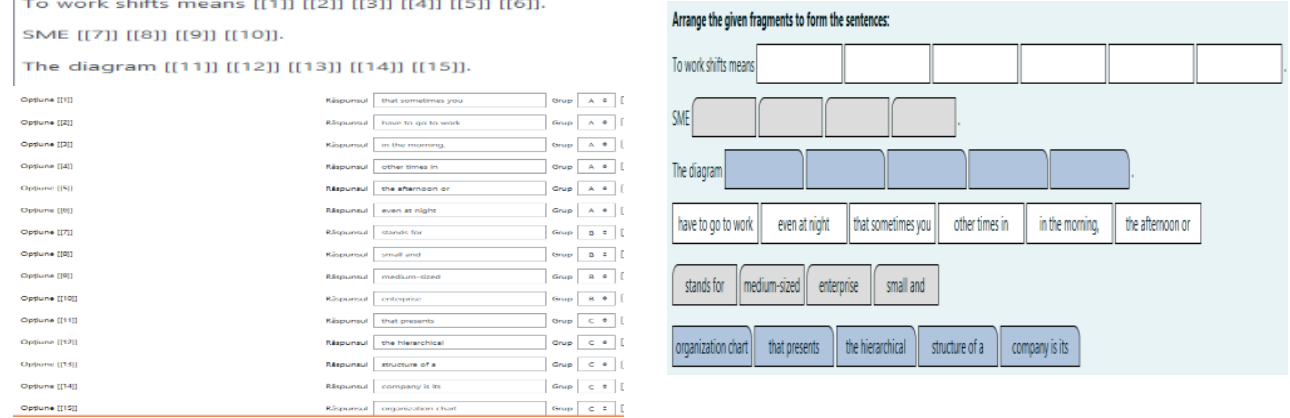

Figure 12. Coding and result for arranging fragments in order

\subsubsection{Combined answer types}

The following model features a combination of several instructions; the students will have to fill in with right words, choose from variants, find and write synonyms etc. For this, coding instructions for short answer, numeric answer and multichoice answer types will be used, combined as desired, the coding page and the resulting exercise being presented in figure 13.

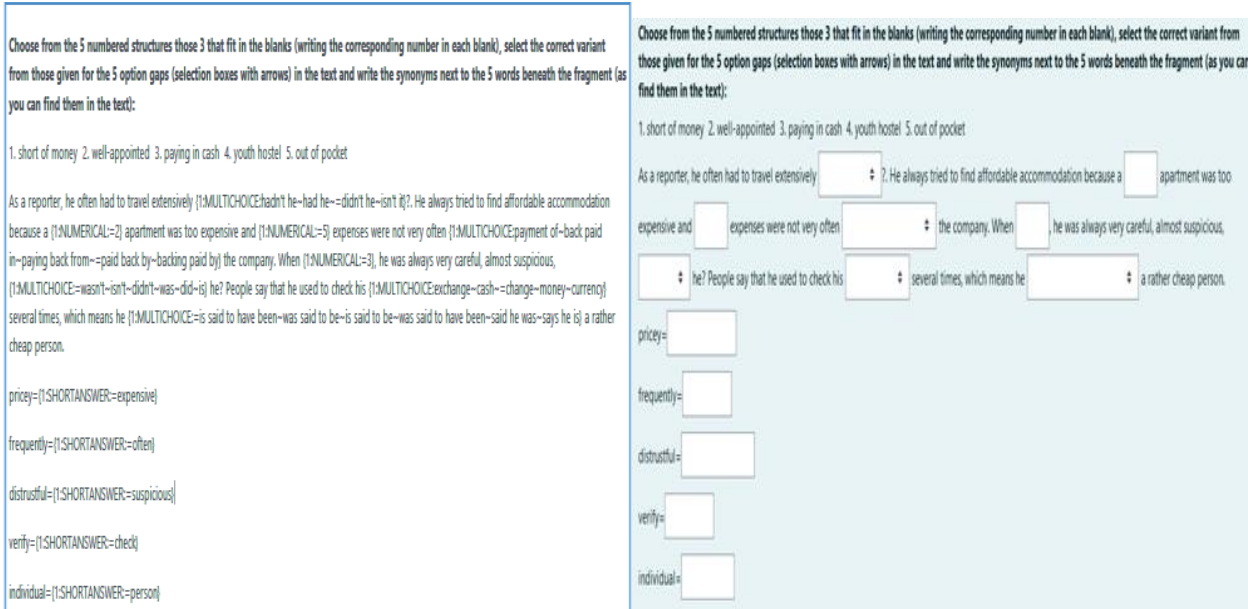

Figure 13. Coding and result for combined short, numeric and multiple choice answer

\subsubsection{Multiple choice}

Besides the general type of multiple choice drills, with one sentence at a time, tests containing more sentences in one exercise can be drawn up, as we briefly mentioned in a previous subtitle. The variants can be arranged either horizontally or vertically, or within the text and accessible from the selection arrow buttons, or after each sentence/ fragment or at the end a.s.o.

A. with variants displayed at selection arrow buttons within the text 
Choose the right structures:

Banks [1:MULTCHOICE: providing = provide provision) their customers with a [1:MULTCHOICE: numerous numbered $n=$ number] of services. With a checking (1:MULTCHOICE: count accountant $\sim$ =account) you can (1:MULTCHOCE: play pray $\sim$ =pay\} your bills, A check is a slip of paper \{1:MULTICHOCE: this = that whe\} tells the bank (1:MULTCHOICE: how many $w=$ how much so much) money it should withdraw \{1:MULTCHOICE; for you = from your from you\} acCount and (IIMULTICHOCE: pays at $\sim=$ =pay to paid for) someone else. Today, more and (1:MULTCHOICE: more peoples most peoplew=more people\} use the internet banking service, to paj [1:MULTCHOCCE: there bill whey bills $=$ their bills\}, Banks \{1:MULTICHOICE: give, too $=$ al5O give as well giventheir customers plastic cards (1:MULTICHOICE: which with w = with which which is) they can (1:MULTCCHOICE: get moneys = get money be got money) from their account everywhere (1:MULTCHOICE: ant $\sim$ end $\sim$ and) whenever they want.

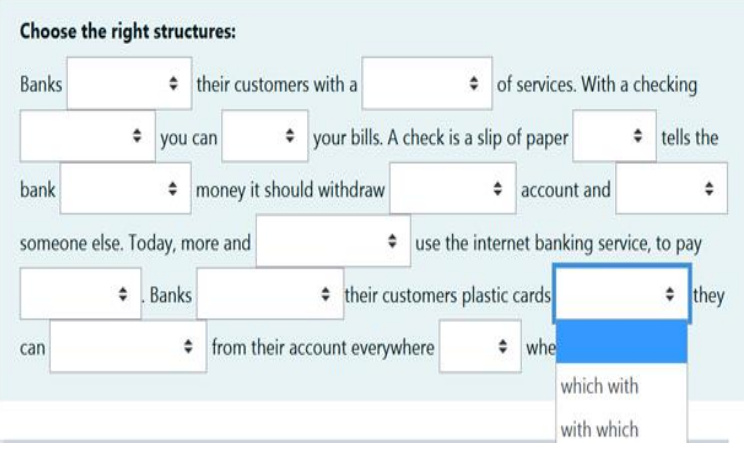

\section{B. horizontally, displayed after the text}

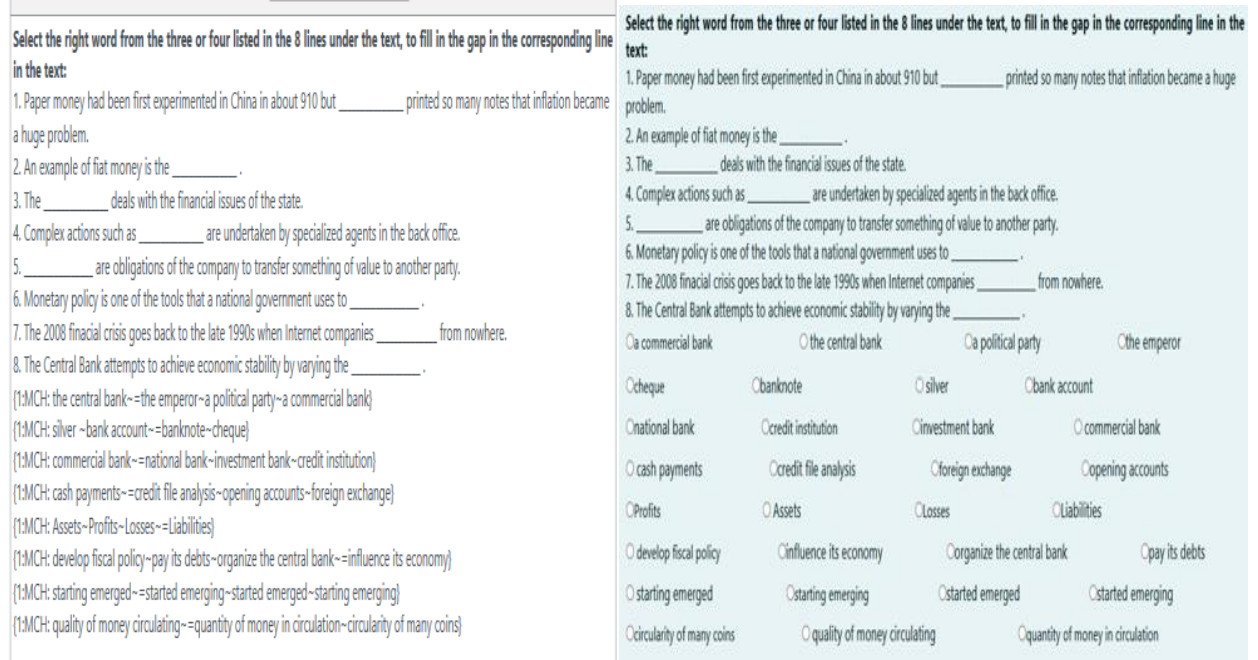

\section{C. horizontally, displayed after each sentence}
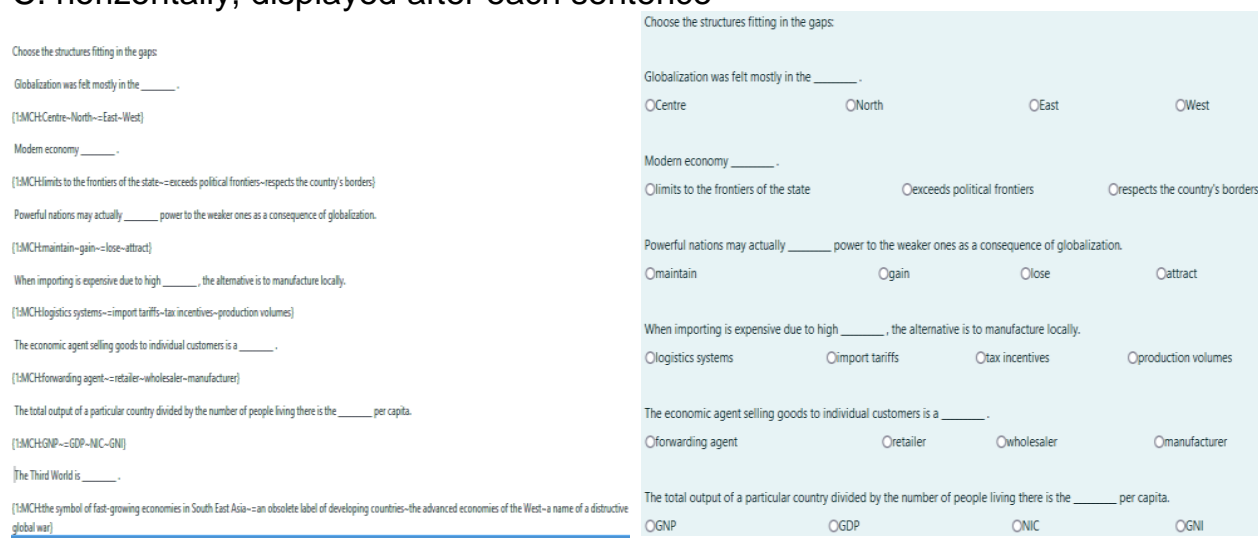

D. vertically, displayed after each sentence 
The Annals of the University of Oradea. Economic Sciences TOM XXX, $2^{\text {nd }}$ Issue, December 2021
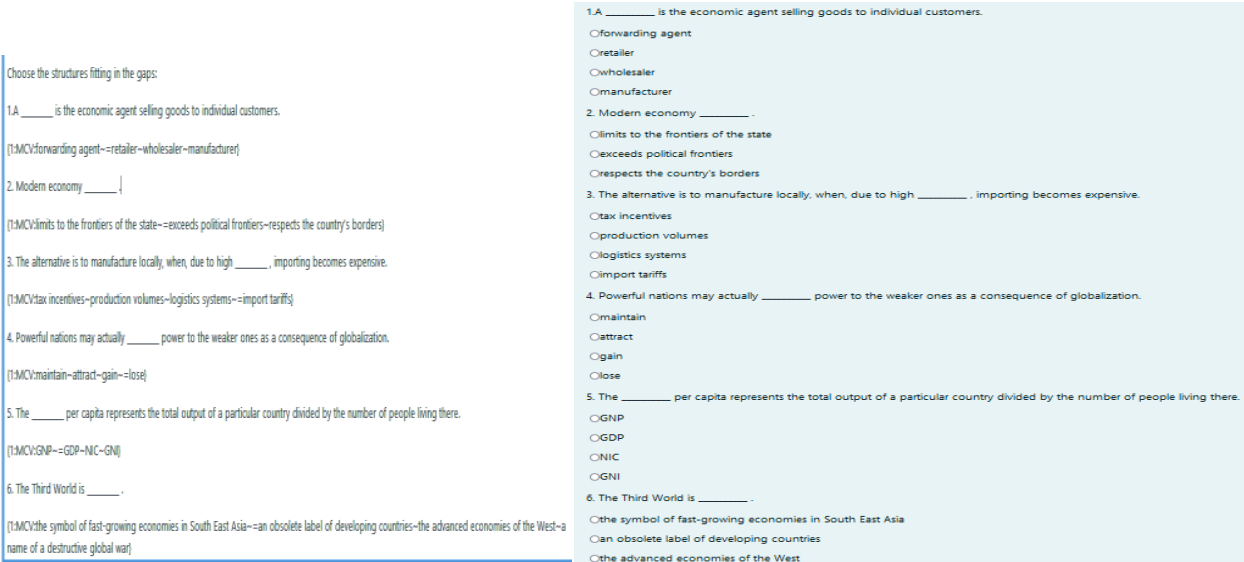

Figure 14 A-D Coding and result pages with various displays for multiple choice drills in one single exercise

Four examples can be seen in the images constituting figure 14 (A-D), and having design explanations before each, as seen above.

The instructions used were 'multichoice' (for A), 'mch' (for B and C) and 'mcv' (for D). Mch and mcv have to be positioned according to the display desired for the final exercise: either after each sentence or below the whole text, the end result following the same structure.

\subsubsection{Word formation}

As incidentally mentioned in the first subtitle, the 'shortanswer' instruction is best used with words that are to be written by the students from the keyboard, as following diverse indications. Some of the most common refer to changing the grammar value of given words so as to fit in the text, namely word formation by derivation and affixation. Others may refer to simply writing the missing words according to the requirements given by close vocabulary elements, lexical structures, idiomatic expressions, collocations or grammar rules. Figure 15 shows the production and the end result of an exercise based on suffixation.
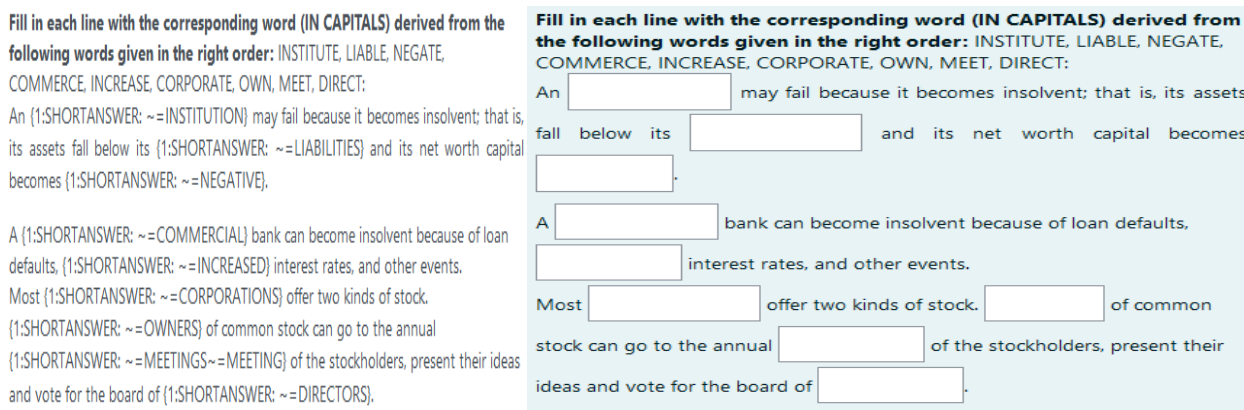

Figure 15. Coding and result for derived words 


\section{Conclusion}

TOM XXX, $2^{\text {nd }}$ Issue, December 2021

This article presented only some examples of the multitude of online exercises, activities and tests, produced on the Moodle platform for the classes of Business English taught by the authors during the academic year 2020-2021. It was a challenging year both for students and for academic staff.

Rewarding as it is to see the appealing, effective and innovative exercises, as the results of the designing Moodle activities, assignments and tests prove to be for Business English classes, the amount of work behind them is also to be taken into consideration. It is indeed a sensitive topic for teachers and language instructors and an important factor in assessing worthiness of the entire process. However, one aspect is very relevant in evaluating the advantages: once created, these activities are easily importable from one page of the platform to another page managed by the same teacher. Thus, they can be useful resources for many classes, series of students, several years forward, or can, if needed, become the starting point for further developed exercises, with small changes brought to the already designed material.

Hard times ask for extra effort in all aspects, but, with proper management of resources and willingness to later integrate the acquired innovative approaches into the system that will one day reach normality again, the entire endeavour put into the production of the educational, language practice and testing resources can surely pay off. It is one big strive in these pandemic times that has the potential of becoming a true asset for the institutions that are open to implementing hybrid- and e-learning. If best used, properly assessed and later integrated in a revolutionary system willing to keep what is good from these times, these educational resources can only bring development and progress to the teaching and learning process and to the institution itself.

\section{References}

1. Aikina, Tatiana Yurievna; Sumtsova, Olga Vitalievna; Pavlov, Dmitriy Igorevich "Implementing Electronic Courses Based on Moodle for Foreign Language Teaching at Russian Technical Universities", International Journal of Emerging Technologies in Learning (iJET), Vol 10, No 3 (2015), [Online], Available: jet/article/view/4501, [June 19, 2021]

2. Bird, Phil "Creative Ideas for Language Learning with Moodle", Oxford University Press ELT, English Language Teaching Global Blog, June 1, 2010 , [Online], Available: https://oupeltglobalblog.com/2010/06/01/creative-ideas-for-languagelearning-with-moodle/, [June 19, 2021].

3. "Describing charts. Writing - intermediate B1", Bristish Council, Learn English, Online], Available: https://www.google.com/imgres?imgurl=https\%3A\%2F\%2Flearnenglish.bri tishcouncil.org\%2Fsites\%2Fpodcasts\%2Ffiles\%2FWriting-B1-Describingcharts-

3.png\&imgrefurl=https\%3A\%2F\%2Flearnenglish.britishcouncil.org\%2Fskill s\%2Fwriting\%2Fintermediate-b1\%2Fdescribing- 
charts\%3Fpage\%3D1\&tbnid=I-

UMuqAspDKeQM\&vet=12ahUKEwjBvtaot6TxAhVLwqQKHZrzANQQMyg AegUIARCvAQ..i\&docid=MeheZyfjJIVvOM\&w=3000\&h=3000\&q=smartph one\%20graph\%20description\%20english\&client=firefox-b-

d\&ved=2ahUKEwjBvtaot6TxAhVLwqQKHZrzANQQMygAegUIARCvAQ, [October, 2020].

4. Gluchmanova, Marta "Using the Moodle Platform in English Teaching", TEM Journal. Volume 5, Issue 4, Pages 492-497, ISSN 2217-8309, DOI: 10.18421/TEM54-13, November 2016, [Online], Available: https://www.google.com/search?q=moodle+in+teaching+languages\&client $=$ firefox- $b-$

d\&sxsrf=ALeKk03QEl64ypLL5zqFZ4M2lySoVUZF5A\%3A1624116645735 \&ei=pQ3OYMikLKL-

7_UP8OKeiAs\&oq=moodle+in+teaching+languages\&gs_lcp=Cgdnd3Mtd2 I6EAM6BwgAEEcQsANQsENYIF1g2mVoAXABeACAAdMBiAGrA5IBBTA uMi4xmAEAoAEBqgEHZ3dzLXdpesgBCMABAQ\&sclient=gws-

wiz\&ved=0ahUKEwili_jgaTXAhUi_7sIHXCxB7EQ4dUDCA0\&uact=5, [June 17, 2021].

5. Khabbaz, Majid; Najjar, Rasool "Moodle-based Distance Language Learning Strategies: An Evaluation of Technology in Language Classroom", International Journal of Applied Linguistics and English Literature IJALEL, Vol 4, No 4 (2015), [Online], Available: https://www.journals.aiac.org.au/index.php/IJALEL/article/view/1451, [June 21, 2021].

6. Stanford, Jeff Moodle 1.9 for Second Language Teaching, Packt, 2009, [Online], Available: https://www.packtpub.com/product/moodle-1-9-forsecond-language-teaching/9781847196248, [June 18, 2021].

7. Suksan, Suppasetseree; Nutprapha, K. Dennis "The Use of Moodle for Teaching and Learning English at Tertiary Level in Thailand", January 2010, International Journal of the Humanities 8(6):29-46, [Online], Available:

https://www.researchgate.net/publication/291281931_The_Use_of_Moodl e_for_Teaching_and_Learning_English_at_Tertiary_Level_in_Thailand, [June 17, 2021].

8. Warth-Sontheimer, Claudia "Using Moodle for Language Teaching. A Guide to Moodle Activities for the Language Classroom", Comenius Network Wide Minds (WiMi), University of Tübingen, 2011, [Online], Available:

https://www.academia.edu/620127/Using Moodle for Language Teachin g_A_Guide_to_Moodle_Activities_for_the_Language_Classroom, [June $21,2021]$. 